\title{
COLLABORATIVE AND CONSULTATIVE PATIENT AND PUBLIC INVOLVEMENT IN SEXUAL HEALTH RESEARCH: LESSONS LEARNED FROM FOUR CASE STUDIES
}

\author{
Lorraine K McDonagh ${ }^{1,2}$ \\ Paula Blomquist ${ }^{2,3}$ \\ Sonali Wayal ${ }^{2,4}$ \\ Sarah Cochrane $e^{5}$ \\ Josina Calliste ${ }^{2}$ \\ Jackie Cassell $^{2,6}$ \\ Natalie Edelman ${ }^{7}$ \\ ${ }^{1}$ Research Department of Primary Care and Population Health, University College London, London, UK, \\ NW3 2PF \\ ${ }^{2}$ National Institute for Health Research Health Protection Research Unit in Blood Borne and Sexually \\ Transmitted Infections at University College London, in partnership with Public Health England and in \\ collaboration with London School of Hygiene \& Tropical Medicine, London, United Kingdom \\ ${ }^{3}$ Blood Safety, Hepatitis, Sexually Transmitted Infections (STI) and HIV Division, Public Health England, \\ London, UK, NW9 5EQ \\ ${ }^{4}$ Centre for Population Research in Sexual Health and HIV, Institute for Global Health, University College \\ London, London, UK, WC1E 6BT \\ ${ }^{5}$ Unity Sexual Health, University Hospitals Bristol, NHS Foundation Trust, UK, BS2 0JD \\ ${ }^{6}$ Department of Primary Care and Public Health, Brighton and Sussex Medical School, University of \\ Brighton, Brighton, UK, BN1 9PH \\ 7 Centre for Health Research, School of Health Sciences, University of Brighton, Falmer, East Sussex BN1 \\ $9 \mathrm{PH}$
}

CORRESPONDENCE TO: Dr Lorraine K. McDonagh; 1.mcdonagh@ucl.ac.uk 


\begin{abstract}
Objectives

Patient and Public Involvement (PPI) is increasingly mandated in health research. However, there is little guidance on conducting PPI for research on episodic infections, risk factors, hard-to-reach populations, or stigmatised behaviours. The aim of this paper is to address the gap in PPI guidance by illustrating different approaches to challenging PPI scenarios.
\end{abstract}

\title{
Methods
}

Four case studies of sexual health research PPI, each of which discusses three stages of PPI (defining, accessing and engaging with lay advisors).

\section{Results}

Researchers may need to use broadly define lay advisors; involving those with insight into population of interest can be beneficial. Alternative and multiple routes to access patients/public should be considered. Flexible means of engagement can enable lay advisors to contribute anonymously, remotely and/or opportunistically.

\section{Conclusions}

Case studies may help researchers in sexual health (and other fields) to better meet the challenges of PPI for studies which concern hard-to-reach populations, episodic infections, risk factors, and stigmatised behaviours.

Keywords: patient and public involvement, hard-to-reach populations, episodic infection, stigmatised behaviours 


\section{BACKGROUND}

Patient and Public Involvement (PPI) refers to research carried out "with" or "by" members of the public rather than "to", "about" or "for" them ${ }^{1}$. PPI can include patients, carers, service users and the public, referred to here as 'lay advisors' (can also be called PPI experts, public advisors, stakeholders, experts by experience). PPI entails contributing in varying degrees to the design, development, conduct, data analysis, and dissemination of research ${ }^{2}$. Involvement can be consultative (single episode), collaborative (ongoing), or user controlled (actively controlled, directed and managed by service users) ${ }^{3}$.

PPI is now commonly required in research funding proposals. There are national UK standards for conducting $\mathrm{PPI}^{4}$, and considerable guidance on how to identify and engage with lay advisors (e.g., tailoring PPI to the needs of the study and the willingness of representatives ${ }^{5}$ ), and how to evaluate the impact of $\mathrm{PPI}^{6,7}$. Most guidance addresses PPI in the context of intervention studies and/or long-term conditions (including long-term stigmatised conditions $)^{8}$ whereby lay advisors are sought through regular clinic attendance, patient support groups, or charities. In contrast, there is little guidance or precedence on conducting PPI for episodic infection involving singular attendance (e.g., chlamydia), for studies which seek to describe population characteristics or risk factors, or for study populations defined by stigmatised behaviours ${ }^{9}$. Much sexual health research fits within one of these scenarios, making PPI in this field challenging ${ }^{9-11}$.

The aim of this paper, therefore, is to share experiences of conducting PPI in sexual health research. Successes and failures from four studies are discussed (see Table 1 for an overview of each study). Lessons learned are presented in relation to three stages of PPI activities: 1) determining who to include as lay advisors; 2) identifying where to access lay advisors; and 3) engaging with those who have agreed to be involved. 
PPI FOR SEXUAL HEALTH RESEARCH

Table 1: Summary of case studies for PPI in sexual health research

\begin{tabular}{|c|c|c|c|c|c|c|}
\hline Study name & Study aim & $\begin{array}{l}\text { Why PPI was } \\
\text { difficult }\end{array}$ & $\begin{array}{l}\text { Who were lay } \\
\text { advisors }\end{array}$ & $\begin{array}{l}\text { How were lay } \\
\text { advisors accessed }\end{array}$ & $\begin{array}{l}\text { How the team } \\
\text { engaged with lay } \\
\text { advisors }\end{array}$ & How the study benefited \\
\hline $\begin{array}{l}\text { Case study 1: } \\
\text { CaWWRiS }\end{array}$ & $\begin{array}{l}\text { To understand the social, } \\
\text { cultural, and historical } \\
\text { factors linked to poor } \\
\text { sexual health for young } \\
\text { Black Caribbean women }\end{array}$ & $\begin{array}{l}\text { Few organisations } \\
\text { are commissioned to } \\
\text { deliver sexual health } \\
\text { services specifically } \\
\text { to Black Caribbean } \\
\text { communities }\end{array}$ & $\begin{array}{l}\text { Black Caribbean } \\
\text { women working in } \\
\text { sexual health } \\
\text { organisations with } \\
\text { Black Caribbean } \\
\text { young people }\end{array}$ & $\begin{array}{l}\text { Networking at } \\
\text { relevant events and } \\
\text { reaching out to } \\
\text { sexual health } \\
\text { organisations }\end{array}$ & $\begin{array}{l}\text { One-to-one and } \\
\text { group consultation } \\
\text { (in person) }\end{array}$ & $\begin{array}{l}\text { Supported development of } \\
\text { age- and culturally- } \\
\text { appropriate content and } \\
\text { terminology in recruitment } \\
\text { materials, helped design } \\
\text { topic guide for qualitative } \\
\text { research }\end{array}$ \\
\hline $\begin{array}{l}\text { Case study 2: } \\
\text { PADCAT }\end{array}$ & $\begin{array}{l}\text { To develop a clinical } \\
\text { prediction rule to identify } \\
\text { women attending GPs who } \\
\text { would benefit from sexual } \\
\text { health advice, STI testing } \\
\text { and/or contraceptive } \\
\text { advice and supply }\end{array}$ & $\begin{array}{l}\text { Risk group is not } \\
\text { well-described - } \\
\text { study was seeking to } \\
\text { define them }\end{array}$ & $\begin{array}{l}\text { Female GP } \\
\text { attendees aged 16- } \\
44 \text { years }\end{array}$ & $\begin{array}{l}\text { Opportunistic } \\
\text { consultation of } \\
\text { patients in GP } \\
\text { surgeries awaiting } \\
\text { an appointment }\end{array}$ & $\begin{array}{l}\text { One-to-one } \\
\text { consultation } \\
\text { (online and in } \\
\text { person) }\end{array}$ & $\begin{array}{l}\text { Shaped data collection } \\
\text { methods, ordering and } \\
\text { composition of questions } \\
\text { for tool, and content and } \\
\text { format of participant } \\
\text { information sheet }\end{array}$ \\
\hline $\begin{array}{l}\text { Case study 3: } \\
\text { YS Study }\end{array}$ & $\begin{array}{l}\text { To explore barriers and } \\
\text { facilitators to chlamydia } \\
\text { testing via general practice } \\
\text { for young people. }\end{array}$ & $\begin{array}{l}\text { Chlamydia is an } \\
\text { episodic infection }\end{array}$ & $\begin{array}{l}16-24 \text { year old } \\
\text { from general } \\
\text { public }\end{array}$ & $\begin{array}{l}\text { Advertisements on } \\
\text { online social } \\
\text { media platforms }\end{array}$ & $\begin{array}{l}\text { One-to-one } \\
\text { consultation } \\
\text { (online) and group } \\
\text { consultation (in } \\
\text { person) }\end{array}$ & $\begin{array}{l}\text { Development of study } \\
\text { materials (the name of the } \\
\text { study, the study logo and } \\
\text { recruitment materials), } \\
\text { participant information } \\
\text { sheets, potential } \\
\text { recruitment strategies }\end{array}$ \\
\hline $\begin{array}{l}\text { Case study 4: } \\
\text { MSHSMW }\end{array}$ & $\begin{array}{l}\text { To identify the sexual } \\
\text { healthcare needs among } \\
\text { women with problematic } \\
\text { drug use. }\end{array}$ & $\begin{array}{l}\text { Drug use is a } \\
\text { stigmatised } \\
\text { behaviour }\end{array}$ & $\begin{array}{l}\text { Women who were } \\
\text { engaged in drug } \\
\text { treatment }\end{array}$ & $\begin{array}{l}\text { Role descriptions } \\
\text { distribute by staff } \\
\text { at NHS drug } \\
\text { service }\end{array}$ & $\begin{array}{l}\text { Group consultation } \\
\text { (in person) and } \\
\text { remotely (via } \\
\text { postal services) }\end{array}$ & $\begin{array}{l}\text { Informed recruitment } \\
\text { strategies, study } \\
\text { advertisement plan, data } \\
\text { collection materials, and } \\
\text { dissemination }\end{array}$ \\
\hline
\end{tabular}




\section{STAGE 1: WHO TO INCLUDE AS LAY ADVISORS}

Ideally, lay advisors are individuals who fit the criteria of being a prospective endusers - i.e., they belong to the population who stand to benefit from the study findings. However, lay advisors offer lay perspective and thus should not be expected to be representative of all those who might comprise the intended study population ${ }^{3}$. Nonetheless, divergent opinions (including backgrounds and experiences) should be sought. Lay advisors will have their own priorities and reasons for involvement, and as such a diversity in views will help ensure the research produced is holistic and that PPI activities are inclusive and meaningful rather than tokenistic.

It may not always be possible to include potential end-users if the population is particularly hard to reach (e.g., prison populations, disenfranchised groups or social and cultural minorities). In such instances, it may be beneficial to engage instead with individuals who work with and so have insight into the target population, as was the situation in Case Study 1 .

It can also be difficult to conduct PPI for epidemiological studies for which the target population is not well-described (precisely because the study is seeking to identify those descriptors). In such cases, the end-users of a study may need to be defined in terms of broader demographics, locations, or other proxies. Broadening or thinking creatively around the definition of end-user may enable greater levels of consultation and collaboration. This is illustrated in Case Study 2 in which the definition of end-user was broadened due to the stigma associated with the outcome behaviours of interest and because the sociological descriptors of this population were unknown (and sought in the study).

Regarding episodic and easily treatable infections (such as chlamydia), it may be more relevant - and easier - to access the general public, as highlighted in Case Study 3. However, the ease of accessing individuals within that definition should also be considered. 
For example, as described in Case Study 3, the population of interest was 15 to 24 year olds. As including individuals below 16 years of age would have required parental consent ${ }^{12}$, the researchers opted to include those aged 16 and over.

\section{STAGE 2: WHERE TO ACCESS LAY ADVISORS}

In lieu of accessing lay advisors via traditional routes to PPI (e.g., patient-centred communities, organisations, charities and services), our studies capitalised on other routes. These included: opportunistic networking at public events and conferences, and conversations via existing social and professional networks (Case Study 1); leaflets distributed during medical consultations and opportunistic approach in clinical settings (Case Study 2 and 4) and advertisements on social media platforms (e.g., Facebook, Instagram, Twitter; Case Study 3). Any approach to finding lay advisors outside of the research community can be effective. Proactiveness and creativity from researchers are key, particularly if stigma can act as a disincentive for lay advisors.

In addition to the message content, the style of the invitation and use of language may impact the likelihood of successfully accessing lay advisors. Academic terminology and jargon, particularly that which attempts to encapsulate or define risk groups, may act as a

disincentive to that particular group ${ }^{5}$. As can be seen from Case Study 2, redefining the endusers meant that women were approached for consultation purely on the basis of their attendance at a GP, without the need to describe themselves as at risk of STIs or unintended pregnancy as part of that process.

\section{STAGE 3: HOW TO ENGAGE WITH LAY ADVISORS}

PPI guidance for all types of research states that, from the outset, researchers should clarify the remit and goal of PPI activities ${ }^{4}$. It should also be evident how PPI differs from 
research particularly qualitative research ${ }^{13}$, which can cause confusion if lay advisors are invited in similar ways to participant recruitment or if an advisory group is consulted on a one-off basis. The importance of this distinction cannot be understated for research on stigmatised conditions or behaviours. This should be discussed during initial meetings with lay advisors, as well as being stated in advertisements and role descriptions (during the access phase above). Additionally, the scope of involvement and intentions of each party should be discussed in order to avoid misunderstandings or tensions due to conflicting agendas (such as those that may arise from scientific hierarchical power dynamics ${ }^{14}$ ). Transparency is essential in order to build positive working relationships based on mutual trust and respect.

A particular concern when working in sexual health and stigmatised behaviours is that lay advisors may wish to keep their involvement in research private ${ }^{11}$. Researchers should explore and be responsive to lay advisors preferences regarding communication to make it less threatening and easier to become involved. Lay advisors should be given various methods and options for involvement so they can contribute in whatever way they are most comfortable with. This can range from of anonymous, one-to-one, remote conversations to group discussions with a friend (Case Study 3), and can involve the use of pseudonyms and/or online communication (Case Study 2 and 3). Similarly, if training is to be provided to lay advisors, it also needs to be conducted in a way that maintains anonymity and/or confidentiality, such as utilising online resources.

From a practical standpoint, it may be necessary to over-invite in order to: 1) compensate for lay advisors who drop-out; 2) balance those who cannot commit to collaborating throughout the project; 3) ensure a range of views are heard; and 4) allow tasks/roles to be shared amongst lay advisors to alleviate advisor burden. For example, in Case Study 2, role description forms inviting lay involvement were handed out to as many women as possible for these reasons. In Case Study 4, six women initially were enrolled to be 
involved, however, only one stayed involved for the duration of the study. Perhaps for this study, it would have been more beneficial to distribute tasks to multiple advisors, rather than expecting all six to be involved for full duration of project.

\section{CONCLUSION}

Evidently, existing PPI guidance has limited utility for sexual health research. As illustrated through our case studies, innovative and flexible approaches are required which operate ethically and within the broader purposes of PPI, and ultimately widen opportunities for patients and the public to have a voice in research which impacts them.

In relation to determining who to include as lay advisors, it is important to keep in mind that lay advisors offer lay perspective - the goal is not to seek full representation from the target population. Additionally, much can be gained through expanding definitions of end-users and involving those with insight (such as professional proxies) into population of interest. Researchers should also consider alternative routes to access, as traditional routes to PPI may not be fruitful for episodic infections and stigmatised behaviours and experiences. It is essential to avoid academic terminology and jargon in adverts and to ensure that the enduser population is described in acceptable terms - a lesson which applies to PPI across all health domains. Lastly, due to the very nature of sexual health research, lay advisors may wish to remain anonymous; researchers should provide lay advisors with variability regarding preferred method of communication and involvement, in particular harnessing online and other remote means of conversing.

Several limitations warrant mention. For these case studies, PPI was conducted after funding was secured and study aims were set. Future research may benefit from involving lay advisors earlier in the process to help identify research priorities. Another PPI approach which may be fruitful is "user-controlled PPI", whereby patients and the public design and 
conduct the research. Future research may also benefit from the application of research methodologies, such as co-production, which place patients/public and professionals on an equal footing through every stage of the research project ${ }^{15}$.

Through our struggles in conducting PPI, we became aware of how defining endusers, approaching them, and finally engaging with them as lay advisors were distinct challenges, but also opportunities for innovation. PPI does not need to be overly prescriptive; essentially, we were researchers seeking insight from individuals outside of the research community. We made it less threatening and easier for the public to get involved by offering numerous ways of communicating, from group round-tables to one-to-one Skype conversations. We found that respectful, communicative, and mutually beneficial relationships between the researcher and lay advisors, underpinned by clear PPI goals for each study, was essential to successful PPI, and ultimately for successful and impactful research. Careful and considered planning of all these different elements cannot be understated; tools such as our PPI Planning and Assessment form available in Appendix 1 can be useful to this end.

Evidently, there is no single unified patient or public voice - preferences, motives, and intentions will naturally differ. As such, no single approach for conducting PPI is ideal. Researchers must consider what is best for patients and public, what is actually required for their research, and must carefully consider issues of representativeness, diversity, tokenism, and power ${ }^{16}$ before embarking down this path. It is hoped this paper will offer others - both within and outside of sexual health research - the opportunity to learn from our failures and successes, particularly when doing 'difficult' PPI. 


\author{
Abbreviations \\ CaWWRiS = Caribbean Women, Wellbeing and Risk Study \\ GP $=$ General Practice \\ HPRU = Health Protection Research Unit \\ NIHR = National Institute for Health Research \\ PADCAT $=$ Psychosocial And Demographic Clinical Assessment Tool \\ PPI = Patient and Public Involvement \\ STI = sexually transmitted infection \\ $\mathrm{YS}=\mathrm{You}$ and Sex
}

\title{
Acknowledgements
}

We are grateful to all the patients and members of the public who became involved in our research. We are also grateful to the NIHR HPRU in Blood Borne and Sexually Transmitted Infections Steering Committee: Caroline Sabin, John Saunders, Catherine Mercer, Gwenda Hughes, Greta Rait, Jackie Cassell, Sema Mandal, Tim Rhodes, Samreen Ijaz, Kholoud Porter, William Rosenberg.

\section{Contributors}

NE conceived the idea for the paper. All authors (LMD, PB, SW, SC, JoC, JaC and NE) contributed to writing early drafts of the paper. Case Study 1 was conducted by JoC; Case Studies 2 and 4 were conducted by NE; and Case Study 3 was conducted by LMD. LMD and NE prepared the final manuscript with contributions from all co-authors. All authors read and approved the final manuscript.

\section{Competing interests}

None declared 
PPI FOR SEXUAL HEALTH RESEARCH

\section{Funding}

This paper is an independent research by the National Institute for Health Research. The research is funded by the National Institute for Health Research Health Protection Research Unit (NIHR HPRU) in Blood Borne and Sexually Transmitted Infections at University College London, in partnership with Public Health England and in collaboration with the London School of Hygiene and Tropical Medicine (grant number: HPRU-2012-10023). Case study 4 presents independent research commissioned by the NIHR, under the Research for Patient Benefit Programme (PBPG-0407-13149).

\section{Disclaimer}

The views expressed in this publication are those of the authors and not necessarily those of the NIHR, the Department of Health and Social Care, or Public Health England.

\section{Author statement}

The Corresponding Author has the right to grant on behalf of all authors and does grant on behalf of all authors, an exclusive licence (or non-exclusive for government employees) on a worldwide basis to the BMJ Publishing Group Ltd to permit this article (if accepted) to be published in STI and any other BMJPGL products and sub-licences such use and exploit all subsidiary rights, as set out in our licence http://group.bmj.com/products/journals/instructions-for-authors/licence-forms

\section{Provenance and peer review}

Commissioned; externally peer reviewed 


\section{REFERENCES}

1. INVOLVE. What is public involvement in research? 2018 [Available from: http://www.invo.org.uk/find-out-more/what-is-public-involvement-in-research-2/]

2. Edelman N, Barron D. Evaluation of public involvement in research: time for a major rethink? J of Health Services Research 2016;21:209-11. doi: $10.1177 / 1355819615612510$

3. NIHR. Patient and public involvement in health and social care research: a handbook for researchers 2010 [Available from: https://www.nihr.ac.uk/aboutus/CCF/funding/how-we-can-help-you/RDS-PPI-Handbook-2014-v8-FINAL.pdf]

4. NIHR. National standards for public involvement in research 2018 [Available from: https://sites.google.com/nihr.ac.uk/pi-standards/home.

5. Robinson A. Patient and public involvement: in theory and in practice. The Journal of Laryngology \& Otology 2014;128:318-25. doi: 10.1017/S0022215114000735

6. Boote J, Barber R, Cooper C. Principles and indicators of successful consumer involvement in NHS research: results of a Delphi study and subgroup analysis. $J$ Health Policy 2006;75:280-97. doi: 10.1016/j.healthpol.2005.03.012

7. Hanley B, Morris C, Staley K. An evaluation of the process and impact of patient and public involvement in the advisory groups of the UK Clinical Research Collaboration. London: UK Clinical Research Collaboration 2009.

8. INVOLVE. Briefing notes for researchers: public involvement in NHS, public health and social care research 2012 [Available from: http://www.invo.org.uk/wpcontent/uploads/2014/11/9938_INVOLVE_Briefing_Notes_WEB.pdf]

9. Meyrick J, Gray D, Jones AJSh. Assessing the possibilities and challenges of patient involvement in sexual, reproductive and HIV/AIDS services. 2016;13(3):213-20. 
10. Pepper L. Patient and public involvement in sexual and reproductive health: a new editor, and a new tool. BMJ Sex Reprod Health 2018 doi: 10.1136/bmjsrh-2018-200146

11. Meyrick J, Gray D. Evidence-based patient/public voice: a patient and public involvement audit in the field of sexual health. BMJ Sex Reprod Health 2018;44(4):267-71. doi: 10.1136/bmjsrh-2018-200082

12. INVOLVE. Involving children and young people in research: top tips and essential key issues for researchers 2016 [Available from: http://www.invo.org.uk/wpcontent/uploads/2016/01/involvingcyp-tips-keyissues-January2016.pdf]

13. Pandya-Wood R, Barron DS, Elliott J. A framework for public involvement at the design stage of NHS health and social care research: time to develop ethically conscious standards. Research Involvement \& Engagement 2017;3(1):6. doi: 10.1186/s40900017-0058-y

14. Høeg B, Tjørnhøj-Thomsen T, Skaarup J, et al. Whose perspective is it anyway? Dilemmas of patient involvement in the development of a randomized clinical trial-a qualitative study. 2019:1-8. doi: 10.1080/0284186X.2019.1566776

15. INVOLVE. Guidance on co- producing a research project 2018 [Available from: https://www.invo.org.uk/wp-content/uploads/2018/03/Copro_Guidance_Mar18.pdf]

16. Johannesen J. The trouble with patient and public involvement (PPI). Keynote at Cochrane Colloquium 2018 [Available from: https://johannesen.ca/2018/09/the$\underline{\text { trouble-with-patient-and-public-involvement-ppi-keynote-at-cochrane-colloquium- }}$ $\underline{2018 /]}$ 


\section{Case Study 1: The Caribbean Women, Wellbeing and Risk Study (CaWWRiS)}

One of the aims of this study was to understand the social, cultural, and historical factors associated with poor sexual health in young Black Caribbean women aged under 25 years.

\section{Who to include as lay advisors?}

Black and minority ethnic groups can experience heightened stigma related to STI diagnoses and may be hard-to-reach for researchers. For one component of this study, researchers opted to engage with Black Caribbean women who worked with diverse populations of young people within sexual health organisations. Specifically, lay advisors were not enlisted on the basis of having personally experienced poor sexual health (e.g., an STI diagnosis), but for their experiential insight as women with Black Caribbean heritage and connections to both youth and sexual health professional networks.

\section{Where to access lay advisors?}

To access Black Caribbean women with insight into sexual health and diverse populations of young people, the researchers discussed the project at conferences and events, as well as within their extended professional and social networks. Those who expressed interest were then provided with more detail about the project in individual follow-up informal meetings. Given that the health and wellbeing of Black Caribbean women is often-neglected, these representatives working in the sexual health sector were enthusiastic to support this research.

\section{How to engage with lay advisors?}

Researchers intended to have a lay advisory group, however, three lay advisors preferred to be involved through individual one-to-one discussions, in the first instance. These informal chats allowed the researchers and lay advisors to talk through person-specific concerns that they might not have otherwise been willing to talk through in detail in a group, and helped build a relationship with each individual. Following these initial individual meetings, the lay advisory group met biannually to support the project in the form of group round-table discussions. The advisors had an understanding of the sensitivity of sexual health work with both young people and Black and minority ethnic communities, and provided much knowledge relevant to each stage of the study. 


\section{Case Study 2: The PADCAT Study ("Psychosocial And Demographic Clinical} Assessment Tool")

The aim of this study was to develop a clinical prediction rule to identify women attending general practices (GP) who would benefit from sexual health advice, STI testing and/or contraceptive advice and supply.

\section{Who to include as lay advisors?}

Defining the end-user by high-risk and stigmatised experiences proved problematic. After initial attempts (see following section) no women came forward offering to be involved. Therefore, it was decided to use a new broader definition: any female GP attendee between the ages of 16-44 years, regardless of sexual history.

\section{Where to access lay advisors?}

Despite GP staff distributing the PPI role description to patients during consultation and being advertised on the People in Research website, no women were interested in being involved. Consequently, in addition to broadening the definition of who to include, the researchers decided to predominantly access women opportunistically during their attendance for a GP appointment. In addition, a local youth forum in a deprived area was approached with a view to setting up female-only group consultations.

\section{How to engage with lay advisors?}

The researcher approached women in GP waiting rooms and with their permission discussed study materials and plans while they were waiting for their appointment. Two group consultations were carried out at the youth forum, where recruitment plans and study materials were reviewed and discussed. One young woman also agreed to collaborate as a lay advisor on the condition that she would do so remotely and anonymously using Skype calls and feedback on study documents via email. She remained involved in the project as an active collaborator 


\section{Case Study 3: The YS Study ("You and Sex")}

The aim of this study was to explore barriers and facilitators to chlamydia testing via general practice for young people.

\section{Who to include as lay advisors?}

The population of interest was 15 to 24 year olds as chlamydia rates are highest amongst this age group. The inclusion of those under 16 years, however, was associated with additional hurdles related to collaborating with minors (i.e., the need for parental consent). Thus, the researchers opted to include only those aged 16 and over as lay advisors. Additionally, the team felt it was not necessary for lay advisors to have experienced chlamydia testing or a positive diagnosis, but to have the potential to be offered - i.e., the general public.

\section{Where to access lay advisors?}

The researchers reached out to several young people's charities and organisations requesting any interested parties to contact the researchers; no young people got in touch. Existing young people's PPI committees were contacted but waiting-lists were often long. Subsequently, the team decided to access the population of interest via advertisements on online social media platforms (e.g., Facebook, Instagram, and Twitter). Advertisements directed people to the study page, which included a secure section to enter contact details (phone or email) and the most suitable times/days to be contacted by the researchers. This approach was found to be successful; over 20 young people provided contact details within 24 hours.

\section{How to engage with lay advisors?}

Four young people agreed to be involved in this specific project (note: some who completed the contact form became involved in other related studies being conducted by the team). The researchers originally intended to have a lay advisory panel who met quarterly. However, during initial phone conversations, it became evident that this would not be feasible. Researchers discussed preferred method of communication with each potential advisor; two agreed to collaborate remotely (one via email, one via phone), and two (who were friends) preferred to meet the researchers in person. Lay advisors gave invaluable input on study materials, particularly on the name of the study, the study logo and recruitment materials (e.g., adverts, Facebook pages). Their involvement greatly improved the accessibility of the study. 


\section{Case Study 4: Identifying sexual healthcare needs among women with problematic drug} use

The aim of this study was to identify the sexual healthcare needs among women with problematic drug use.

\section{Who to include as lay advisors?}

The intended end-users of this study were women experiencing problematic drug use, including those not in drug treatment. However, given the sensitive nature of the study, the decision was taken to recruit lay advisors from among those who were actively engaged in drug treatment on the basis that they would be able to draw upon prior knowledge and that safety was paramount.

\section{Where to access lay advisors?}

Role descriptions were provided to key workers at an NHS drug service, and were distributed to clients who met the role criteria. Six women subsequently contacted the research team using the phone number provided on the role description. Of these, two elected to become collaborating members of the research team.

\section{How to engage with lay advisors?}

During an initial phone conversation, the preferred means of engagement were discussed. Both lay advisors chose to attend research team meetings, one of whom received childcare costs from the study team to enable this. Neither advisor had internet access at the start of the study, therefore, in-between meetings, documents were sent for review with a stamp addressed envelope included. One of the lay advisors also elected to co-present the PPI strategy to the Society for the Study of Addiction in order to raise awareness of how PPI is possible with this population. The recruitment strategy, study advertisement plan, data collection materials were all heavily influenced by the lay advice. 
Developed by the Patient and Public Involvement Expert Advisory Group of the NIHR Health Protection Research Unit in Blood Borne and Sexually Transmitted Infections at University College London in partnership with Public Health England and in collaboration with the London School of Hygiene and Tropical Medicine

\section{FUNDED BY}

\section{NIHR $\mid \begin{aligned} & \text { National lnstitute } \\ & \text { tor Health Research }\end{aligned}$}

\section{NIHR Health Protection Research Unit (HPRU) in Blood Borne and Sexually Transmitted Infections (BBSTI)}

\section{Patient and Public Involvement Planning and Assessment Form}

The NIHR HPRU in BBSTIs provides an important opportunity to ensure that the public is at the heart of our research, by facilitating high quality interactions between the research team and the people we are here to serve. Patient and Public Involvement (PPI) is expected in all NIHR HPRU in BBSTI projects.

The HPRU has an active PPI working group, led by research fellows from all three Themes. The group meet regularly and all HPRU members are welcome to attend.

This document presents guidance on how to plan your PPI activities, how to evaluate the impact of these activities, as well as how they should be costed.

PPI proposals should be developed in consultation with the PPI leads for your Theme and will be discussed at the regular meeting of Theme PPI leads.

Please refer to the INVOLVE National Standards on patient and public involvement available at: https://www.invo.org.uk/posttypepublication/national-standards-forpublic-involvement/

Further information is available at:

- http://www.invo.org.uk/

- https://www.ucl.ac.uk/joint-research-office/new-studies/public-and-patientinvolvement 
SECTION 1: STUDY INFORMATION

\begin{tabular}{|c|c|c|}
\hline 1. & HPRU Theme & $\begin{array}{l}\text { A - Understanding risk and risk reduction of BBSTI } \\
\text { B - Reducing the burden of undiagnosed of BBSTI } \\
\text { C - Improving care and management of BBSTI } \\
\text { (Delete as appropriate) }\end{array}$ \\
\hline 2. & Study title & \\
\hline 3. & $\begin{array}{l}\text { Contact name and email } \\
\text { address }\end{array}$ & \\
\hline 4. & Study aims and objectives & \\
\hline 5. & $\begin{array}{l}\text { Lay summary } \\
\text { Please summarise your project } \\
\text { (max } 200 \text { words) }\end{array}$ & \\
\hline 6. & $\begin{array}{l}\text { Study progress } \\
\text { Please summarise which stage } \\
\text { the study is currently at e.g., } \\
\text { planning, data collection, } \\
\text { analysis } \\
\text { (max } 50 \text { words) }\end{array}$ & \\
\hline 7. & $\begin{array}{l}\text { Public involvement work to } \\
\text { date } \\
\text { Please summarise any public } \\
\text { involvement work which is } \\
\text { already taking place or has } \\
\text { been completed in relation to } \\
\text { this study } \\
\text { (max } 200 \text { words) }\end{array}$ & \\
\hline
\end{tabular}




\section{SECTION 2: PATIENT AND PUBLIC INVOLVEMENT PLANS}

\section{Lay advisors}

Who will be the lay advisors or 'end-users' for this study? How many will be involved?

\section{PPI Objectives}

What are the objectives of the planned PPI activity?

3. PPI Co-ordinator

Who is the named PPI coordinator from within the research team?

4. Plans for accessing layadvisors for the study

How will you access lay advisors (e.g., social media, organisations, networking etc.)?

5. Plans for engaging with the lay advisors of the study

How will you engage with lay advisors (e.g., in-person, online forums, existing groups etc.)?

6. Expected Impact

How do you expect the PPI activity to impact your study?

\section{PPI Evaluation Plans}

How do you plan to evaluate the impact of the PPI activity? 


\section{SECTION 3. PATIENT AND PUBLIC INVOLVEMENT EVALUATION}

To be completed post-PPI activity

1. Did the PPI activity meet your objectives?

Please explain why, or why not

2. What impact do you think the PPI activity had on your study?

Did this differ from your expected impact?

Did your research plans change as a result of the activity?

Include:

- impact on research processes and outcomes

- positive and negative impacts

- short and long-term impacts

3. What impact did this activity have on the patients/public who were involved?

Include positive and negative reports of impact 


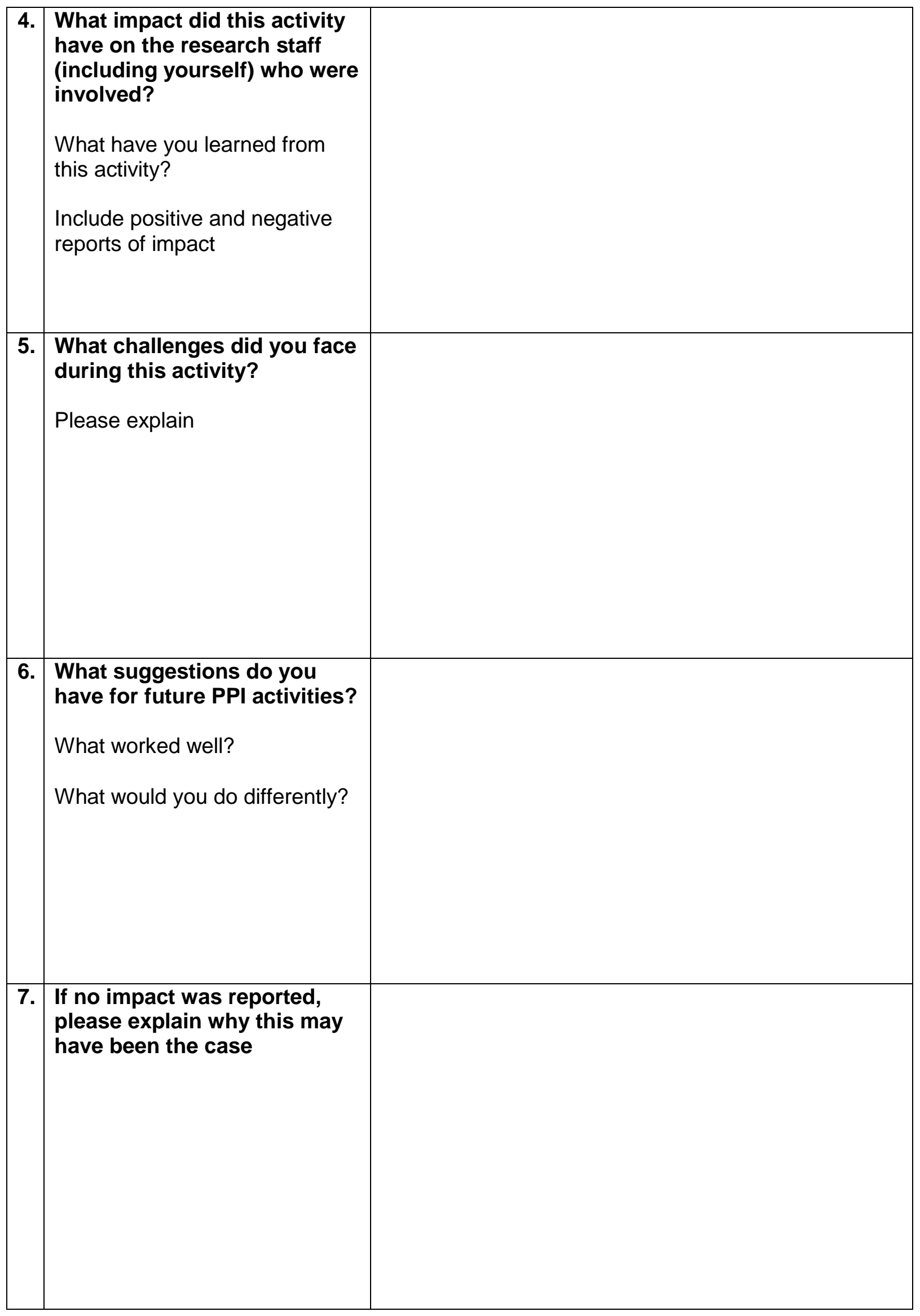


SECTION 4. COSTS AND PERIOD OF SPEND

Spending profile for your activity

\begin{tabular}{|c|c|c|c|c|c|c|}
\hline $\begin{array}{l}\text { Project } \\
\text { name }\end{array}$ & $\begin{array}{l}\text { PPI } \\
\text { activity }\end{array}$ & Theme & Year 15-16 & Year 16-17 & Year 17-18 & Year 18-19 \\
\hline & & & & & & \\
\hline & & & & & & \\
\hline & & & & & & \\
\hline & & & & & & \\
\hline & & & & & & \\
\hline & & & & & & \\
\hline & & & & & & \\
\hline & & & & & & \\
\hline TOTAL & & & & & & \\
\hline
\end{tabular}

Please describe the proposed PPI costs Please refer to the list of possible PPI costs below

\begin{tabular}{|l|l|l|}
\hline Nature of Cost & Amount Requested & Breakdown / Explanation Of Cost \\
\hline & & \\
\hline & & \\
\hline & & \\
\hline & & \\
\hline & & \\
\hline & & \\
\hline & & \\
\hline TOTAL COST: & & \\
\hline
\end{tabular}

\section{Example PPI costs}

- Travel by lay advisors or researchers to attend meetings (for PPI work) - 25p per mile, public transport, taxi costs - as necessary

- Subsistence costs for lay advisors attending meetings - up to $£ 10$ per meal

- Carer/childcare costs to enable lay advisors to attend meetings - as necessary, varies according to individual needs

- Payment of lay advisors (NB 'payment' with vouchers is often preferable where social security benefits may be jeopardised by financial payment) - approx. $£ 20$ per hour $/ £ 75$ per half day

- Relevant training for lay advisors (e.g., research methods, public speaking, use of IT) up to $£ 200$

- Attendance by lay people at relevant conferences - up to $£ 200$

- Admin costs, postage, stationery (e.g., stamped addressed envelopes to enable comment on written documents) - as necessary 